\title{
COMENTÁrio A \\ "Sí MisMo COMO PUEblo: COMUNIDAD EN EL PENSAMIENTO DE M. HEIDEGGER": PUEBLOS COMO NOS-OTROS: ONTOLOGÍAS DESDE AFUERA
}

Mauricio Fernando Pitta ${ }^{1}$

Referência do artigo comentado: MICHELOW, D. B. Sí mismo como pueblo: Comunidad en el pensamiento de M. Heidegger. Trans/form/açáo: revista de filosofia da Unesp, v. 44, n. 4, p. 105-122, 2021.

El artículo "Sí mismo como pueblo: Comunidad en el pensamiento de M. Heidegger”, de Daniel Michelow Briones (2021), se centra en el tema de la alteridad entre los escritos de los años 20 y 30 de Martin Heidegger, con especial atención a la diferencia entre dos modulaciones opuestas de la alteridad: como otredad, categoría derivada de la discusión sobre el coestar (Mitsein), estructura existencial del Dasein relativa a la caída no uno (das Man) y a la "solicitud [Fürsorge] anticipativo liberadora" (MICHELOW, 2021, p. 109) que pone el Yo y el Otro en una "participación exógena en el ámbito común" (MICHELOW, 2021, p. 110); y como comunidad, que no debe tomarse como derivación o expansión de la otredad, pero como modulación distinta de la misma cuestión, resultado de un cambio radical de orientación entre las dos partes del Ser y tiempo, donde es necesario, después de atravesar el primer giro

${ }^{1}$ Doctorando en Filosofía por la Universidade Federal do Paraná (UFPR), Curitiba, PR - Brasil. Pesquisa con financiación del Programa de Demanda Social de CAPES - código 001. (DD https:// orcid.org/0000-0002-9642-4072. E-mail: mauriciopitta@hotmail.com.

https://doi.org/10.1590/0101-3173.2021.v44n4.10.p123

\section{(i)}


del círculo hermenéutico y haber obtenido una primera caracterización del Dasein propio, buscar lo que caracteriza al coestar propiamente histórico del Dasein colectivo o "pueblo" (Volk).

Briones realizó una excelente articulación de esta diferencia en relación con la crítica especializada y la literatura del reconocimiento, demostrando cómo la cuestión del pueblo es fundamental para entender la manera efectiva en que Heidegger entiende la alteridad, en su propio sentido y desde un punto de vista histórico. Además de una excelente exégesis y suficiente estado de arte, el autor, al final del artículo, se posiciona críticamente frente a la tesis del Heidegger sobre la alteridad, señalando lo que se menciona en el propio título del artículo: debido a la necesidad de asumir la propiedad historica más allá de la ensimismamiento del Dasein propio, Heidegger termina concibiendo a la comunidad como un "sí-mismo ampliado" (MICHELOW, 2021, p. 120), sin tensiones internas efectivas y, por lo tanto, sin multiplicidad, cuyos límites están en la idea del suelo (Boden), conceptualización cuyas implicaciones políticas son problemáticas al cambiar la alteridad más allá de los límites de la comunidad y posicionarla, desde el principio, en una relación agonística con lo sí-mismo comunitario, además de hacer explícito el "antisemitismo ontohistórico” (MICHELOW, 2021, p. 116) de Heidegger en la diferencia entre pueblos propios y impropios.

Sin embargo, es posible explorar otra solución al problema de la comunidad. En contra de la tesis de Briones, creo que la conceptualización heideggeriana de la comunidad es problemática no por la relación que tiene con el concepto de lugar o "suelo", sino por lo que yo llamaría un ontoetnocentrismo rígido. En otras palabras, la noción heideggeriana de pueblo presupone una especie cerrada de autodeterminación ontológica que, desde el principio, rechaza cualquier posibilidad de influencia externa, hasta el punto de postular, como Heidegger (1985) haría años más tarde, un relativismo lingüístico-topológico absoluto (KUSCH, 1989), cuya contraparte está en el absolutismo ontohistórico de una ontología sobre las otras y, por lo tanto, de un pueblo sobre los demás. Esto también sobredetermina cómo Heidegger constituirá la relación entre la comunidad y el lugar en los escritos de la década de 1930, y que permanece presente, aunque más veladamente, incluso en su obra post-Segunda Guerra - algo que Paul B. Preciado (2020, énfasis añadido) recientemente llamó "[...] definición inmunitaria de la comunidad según la cual esta se dará a sí misma la autoridad de sacrificar otras vidas, en beneficio de una idea de su propia soberanía." 
Esto significa que el problema no estaría en la consideración de la localidad como constitutiva de toda comunidad, ya que Heidegger estaría correcto al señalar la contradicción topológica entre localidad/comunidad y infinidad/universalidad, tomando la "comunidad máxima" como "[...] una quimera o comunidad imposible.” (MICHELOW, 2021, p. 119). Además, la cuestión misma de la espacialidad, que sigue a Heidegger a sus escritos posteriores, ya estaba presente incluso en Ser y tiempo y textos anteriores, aunque in embryo y de manera poco explorada debido a las aporías inherentes a la obra (SLOTERDIJK, 1998, excursión 4; PITTA, 2017). Esto invalida la hipótesis de que Heidegger sólo pensaría la comunidad en un sentido espacial a partir de la década de 1930.

El problema, de hecho, radica en la forma en que este ontoetnocentrismo comunitario, en el que la comunidad "[...] no se forma [...] con el otro en cuanto tal, sino que en cuanto sí-mismo" (MICHELOW, 2021, p. 120), determina cualquier apertura al Otro, es decir, a los pueblos que escapan de este tipo de ontología histórica arraigada al suelo y que, al principio, podrían estar excluidos de la "casa del ser" greco-alemana, como modulación y desarraigo impropio (Bodenlosigkeit). En este sentido, la consideración de la alteridad, incluso la determinación de la ontología primero por el fenómeno de la alteridad, no es equivalente a la internalización y neutralización del Otro por una comunidad carente de cualquier relación con el lugar. Esto no implica necesariamente una recaída en el onto-etnocentrismo de Heidegger, base decisiva para su antisemitismo ontohistórico y algo visto hoy en ideologías neofascistas como el "etnopluralismo" de la Nouvelle Droite francesa o la obra del ideólogo de extrema-derecha, Aleksándr Dúgin.

El etnopluralismo difiere, por otro lado, de lo que se ha conocido en la antropología contemporánea y en algunas escuelas de filosofía como "giro" o "pluralismo ontológico". Me refiero aquí a obras como las de Eduardo Viveiros de Castro, Tânia Stolze Lima, Bruce Albert, Philippe Descola etc. Aquí, basado en un fuerte apoyo etnográfico, se admite la idea de que, al igual que hay varios pueblos más allá de la noción abstracta, unitaria y problemática de la "humanidad" - este exclusivo club que, según el pensador indígena Ailton L. Krenak (2019), nos relegó al Antropoceno -, también debe haber no sólo varias "culturas", sino varias ontologías en contacto y fricción. Mientras que el etnopluralismo defiende la primera idea, pero rechaza cualquier contacto, exhortando una geopolítica de aislamiento recíproco, los pluralismos ontológicos se basan en la suposición de que ninguna ontología es una isla, 
siendo siempre cruzada, afectada e incluso constituida desde intrusiones externas.

Ilustrativo en esto es el multinaturalismo perspectivista de Viveiros de Castro y Lima, basado en la concepción indígena amazónica de que el cosmos está poblado de "naturalezas" diversas, es decir, distintas ontologías, en una dinámica de indiscernibilidad constante, metamorfética y en "desequilibrio perpetuo" entre "culturas" y "naturalezas". Pueblos como el Araweté y el Yanomami constituyen sus comunidades en una relación de intercambio perenne con la viva y actante "sobrenaturaleza" del exterior, en una especie de "topología de alteridad predatoria" en torno a la idea de que "[...] a 'interioridade' do corpo social é integralmente constituída pela captura de recursos simbólicos - nomes e almas, pessoas e troféus, palavras e memórias - do exterior." (VIVEIROS DE CASTRO, 2015, p. 162). La comunidad y su ontología, en este sentido, son sólo momentos de un intercambio perenne entre alteridades, en un juego predatorio donde las posiciones de presa y predador, Sí-mismo y Otro, nunca están garantizadas definitivamente, ya que uno sólo tiene una ontología y uno sólo forma comunidades a la vista de la alteridad.

Lo que, en definitiva, distingue los pluralismos ontológicos del relativismo topolingüístico de Heidegger y los etnopluralismos de extremaderecha es que, en el primer caso, existe, por un lado, un desplazamiento radical entre la localidad y la primacía ontológica de quienes la ocupan, y, por otro, no hay determinación de una ontología que no dependa de la intrusión del Otro - especialmente Gaia, intrusa que, como "suelo" en sentido radical, no pertenece a nadie, mostrándose irreductiblemente como transcendencia indiferente a todos y cada uno de los pueblos que quieran capturarla como un estandarte por su hegemonía (cf. STENGERS, 2015). Esta es, en fin, la principal lección que comunidades amerindias ha enseñado a nuestros pueblos durante 500 años: somos pueblos en la medida en que somos pueblos otros, es decir, nosotros somos nos-otros, otros de Otros, determinados pela mirada de Otros y siempre constituyendo ontologías desde afuera. 


\section{REFERENCIAS}

HEIDEGGER, M. Unterwegs zur Sprache. V. 12. Frankfurt am Main: Vittorio Klostermann, 1985. (Col. "Gesamtausgabe")

$\mathrm{KUSCH}, \mathrm{M}$. Language as calculus versus language as universal medium: a study on Husserl, Heidegger and Gadamer. Dordrecht: Kluwer Academic, 1989.

LACERDA KRENAK, A. Ideias para adiar o fim do mundo. São Paulo: Companhia das Letras, 2019.

MICHELOW, D. B. Sí mismo como pueblo: Comunidad en el pensamiento de M. Heidegger. Trans/form/açáa: revista de filosofia da Unesp, v. 44, n. 4, p. 105-122, 2021. PITTA, M. F. Do problema da espacialidade em Heidegger à esferologia de Sloterdijk. Synesis, v. 9, n. 1, p. 141-164, 2017.

PRECIADO, P. B. Aprendiendo del virus. El País, 2020. Disponible en: https://elpais. com/elpais/2020/03/27/opinion/1585316952_026489.amp.html. Acceso en: 3 maio 2021.

SLOTERDIJK, P. Sphären I (Mikrosphärologie): Blasen. V. 1. Frankfurt am Main: Suhrkamp, 1998.

STENGERS, I. No tempo das catástrofes: resistir à barbárie que se aproxima. Trad. E. A. Ribeiro. São Paulo: Cosac Naify, 2015.

VIVEIROS DE CASTRO, E. Metafísicas canibais: elementos para uma antropologia pós-estrutural. São Paulo: Cosac Naify; n-1, 2015.

Recebido: $14 / 4 / 2021$

Aceito: 18/4/2021 
PITTA, M. F. 